\section{Unwanted Mutations in PCR Mutagenesis: Avoiding the Predictable}

\author{
Kelly D. Smith, ${ }^{1,2}$ \\ Alicia Valenzuela, ${ }^{1}$ \\ Janet L. Vigna, ${ }^{1,2}$ \\ Kim Aalbers, ${ }^{1}$ and \\ Charles T. Lutz ${ }^{1}$
}

\begin{abstract}
Departments of ${ }^{1}$ Pathology and
${ }^{2}$ Microbiology, University of Iowa, Iowa

City, Iowa 52242
\end{abstract}

PCR is a useful technique for generating site-specific mutations ${ }^{(1,2)}$ and recombinations ${ }^{(3)}$ that has distinct advantages over traditional techniques. Traditional oligonucleotide-directed mutagenesis protocols create a mismatch at the desired position between the template DNA strand and a complementary DNA strand synthesized in vitro. When DNA containing the mismatch is transformed into bacteria, the bacteria correct the mismatch, either introducing the desired mutation or restoring the original nucleotide. ${ }^{(4,5)}$ Because only a fraction of the resulting colonies contain the mutation, screening methods frequently are required to distinguish the desired mutations from the unmutated form.

PCR mutagenesis uses primers that contain the desired mutations to amplify the template DNA. Therefore, all of the amplified DNA contains the desired mutation on both strands, eliminating the requirement for a screening step. In addition, PCR recombination uses overlapping primers to combine segments of DNA. This eliminates the requirement in traditional in vitro recombination methods for restriction endonuclease sites at the point of recombination.

In PCR mutagenesis and recombination, the cloned products must be sequenced to identify any unwanted mutations generated during PCR. Most researchers have reported a low frequency of unwanted mutations, in the range of $0.026 \%{ }^{(1)}$ to $0.25 \%{ }^{(6)}$ per nucleotide. These unwanted mutations can be attributed to Taq polymerase misincorporating deoxynucleotides during template-dependent chain elongation. Thus, Taq polymerase misincorporations are not frequent in PCR mutagenesis and recombination procedures. In addition to polymerase activity, however, Taq polymerase has a terminal transferase-like activity. ${ }^{(7)}$ This activity adds a deoxynucleotide to each 3' end of double-stranded DNA, including PCR products. Molecular techniques, such as DNA cloning and mutagenesis, that utilize PCR must compensate for Taq polymerase terminal transferase-like activity. To overcome problems in the direct cloning of PCR products, new vectors (TA Cloning, Invitrogen, and CloneAmp, GIBCO BRL) capitalize on $\mathrm{Taq}$ polymerase terminal transferase-like activity. To overcome problems in PCR mutagenesis and recombination, the investigator must understand the mechanism of Taq poly- merase terminal transferase-like activity generated mutations.

Typical PCR mutagenesis and PCR recombination protocols use first-round PCR products to prime a subsequent round of PCR. These first-round PCR products may be modified at their $3^{\prime}$ ends. When used to prime a subsequent round of PCR, the modified product may substitute an unwanted deoxynucleotide adjacent to the 3' end of this first-round product. Thus, Taq polymerase terminal transferase-like activity may also cause unwanted mutations in PCR. Here we document that, in contrast to misincorporations, Taq polymerase terminal transferase-like activity-generated mutations are frequent. We also present a mechanism to explain how these mutations arise and how they can be avoided.

\section{MATERIALS AND METHODS}

Figure 1 shows the three methods of mutagenesis used. The first-round reaction is essentially the same for all three methods. Each 100- $\mu$ l reaction mixture contains $100 \mathrm{ng}$ of plasmid DNA, 100 pmoles of each oligonucleotide primer (synthesized on Applied Biosystems 391 PCR-Mate, deblocked, and purified on Sephadex G-25 columns), $200 \mu \mathrm{M}$ dNTPs, $50 \mathrm{~mm} \mathrm{KCl}, 10 \mathrm{~mm}$ Tris- $\mathrm{HCl}(\mathrm{pH} 8.8$ at $25^{\circ} \mathrm{C}$ ), $1.5 \mathrm{mM} \mathrm{MgCl}_{2}, 0.1 \%$ Triton X-100, and 2.5 units of Taq polymerase (Promega). Reactions are overlaid with $100 \mu \mathrm{l}$ of mineral oil and incubated in a thermocycler (MJ Research, Inc.) for 5 min at $94^{\circ} \mathrm{C}$, then $30 \mathrm{sec}$ at $50^{\circ} \mathrm{C}, 60 \mathrm{sec}$ at $72^{\circ} \mathrm{C}$, and $60 \mathrm{sec}$ at $94^{\circ} \mathrm{C}$ for 20 cycles, followed by $30 \mathrm{sec}$ at $50^{\circ} \mathrm{C}$ and $7 \mathrm{~min}$ at $72^{\circ} \mathrm{C}$.

For two-step mutagenesis, separate first-round reactions are performed for each of the two overlapping mutagenic primers. Twenty microliters of each firstround reaction mixture is separated on a $1 \%$ low-melting-temperature agarose gel (FisherBiotech) in TAE buffer. ${ }^{(8)}$ The specific bands are excised and melted at $68^{\circ} \mathrm{C}$ immediately prior to use. In the two-step procedure, the second round of PCR is identical to the first-round reaction except that template DNA consists of equimolar amounts of the agarose-isolated first-round amplification products (5-50 ng of each in a total volume not more than $10 \mu \mathrm{l}$ ) and the a and d primers are used (Fig. 1). 


\section{Technical Tips/IIII I}
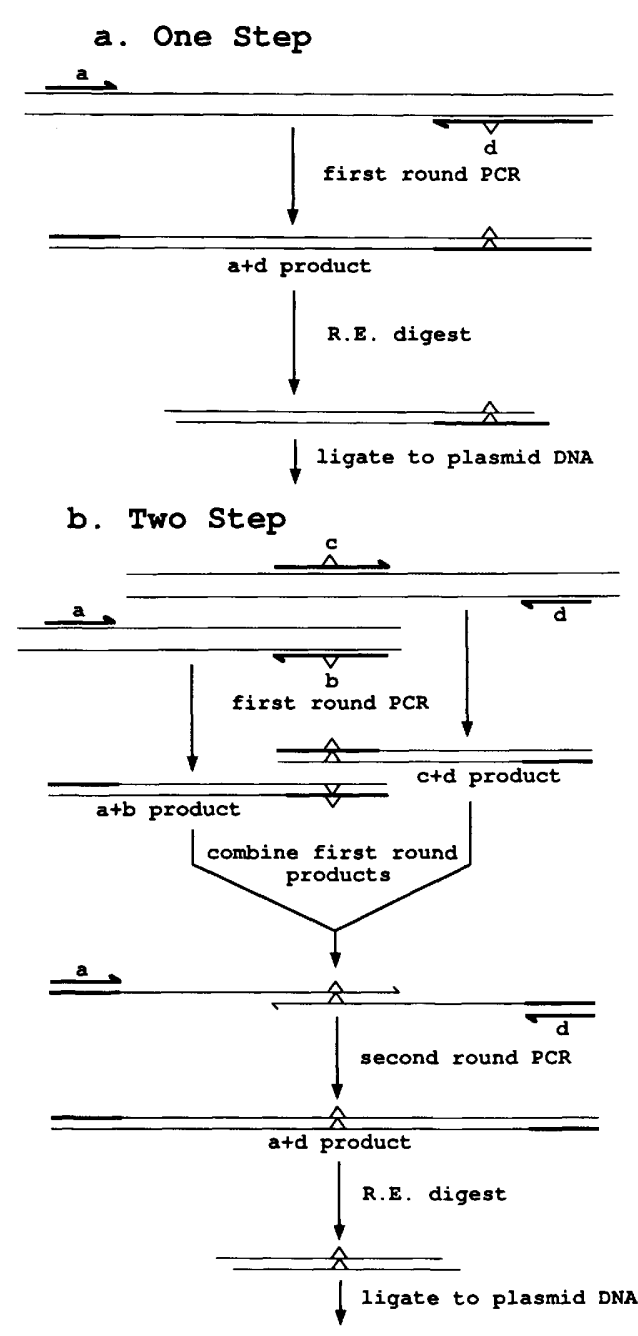

c. Megaprimer

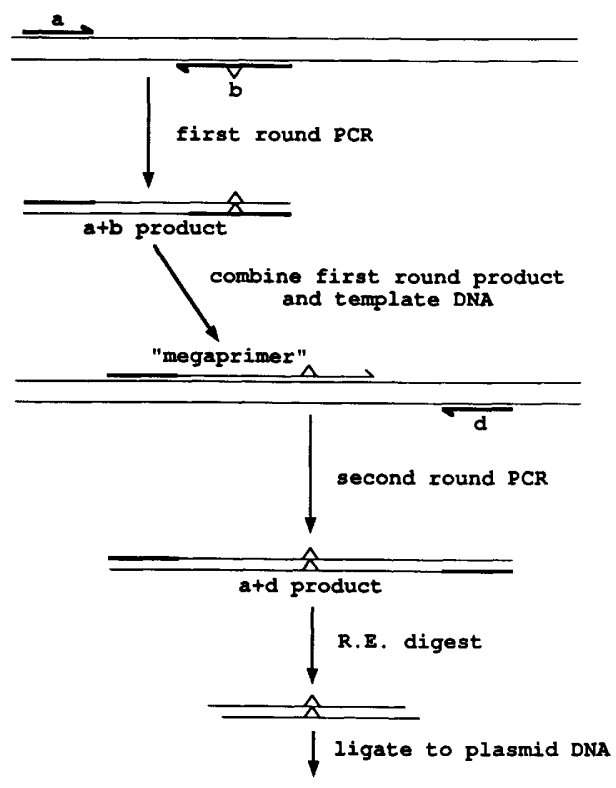

FIGURE 1 PCR mutagenesis methods. (a) In the one-step method, the mutagenic primer (d) contains both the desired substitution (triangle) and a restriction endonuclease (R.E.) site. An external primer (a) is located external to another R.E. site. After one round of PCR, the $\mathrm{a}+\mathrm{d}$ product is digested and subcloned into a plasmid. (b) In the two-step method, two complementary mutagenic primers (b and c) and two external primers ( $a$ and d) are used in two separate first-round reactions. In the second-round of PCR, $a+b$ and $c+d$ products are combined with the external primers, $a$ and $d$. The resulting a $+d$ product is digested and subcloned into a plasmid. (c) In megaprimer mutagenesis, the mutagenic primer (b) and an external primer (a) are used in the first-round of PCR to create the "megaprimer", the $\mathrm{a}+\mathrm{b}$ product. In the second round of PCR, the "megaprimer" and an external primer (d) are used. The resulting $\mathrm{a}+\mathrm{d}$ product is digested and subcloned into a plasmid. In the figure, thick lines denote oligonucleotides and thin lines denote template or PCR synthesized DNA.

For the megaprimer method, one strand of the first-round PCR product serves as a large primer for the secondround PCR. The first-round PCR mixture is concentrated by ethanol precipitation and separated on a $1 \%$ LE agarose gel (SeaKem) in TBE buffer ${ }^{(8)}$; the specific band is excised, electroeluted, precipitated, and resuspended in $\mathrm{H}_{2} \mathrm{O}$. The second-round reaction for megaprimer mutagenesis is essentially the same as the first-round except $100-400 \mathrm{ng}$ of the isolated first-round product, the "megaprimer," is used in place of one of the oligonucleotide primers (Fig. 1).

After cloning PCR products into plasmids, mutations are analyzed by DNA sequencing using Sequenase kit version 2.0 (United States Biochemicals) or cycle-sequencing. ${ }^{(9)}$

TABLE 1 Taq Polymerase Terminal Transferase-like Activity Causes Most of the Unwanted Mutations Seen in PCR Mutagenesis

\begin{tabular}{llccr}
\hline \multirow{2}{*}{$\begin{array}{l}\text { Number of } \\
\text { mutants }\end{array}$} & & \multicolumn{3}{c}{ Unwanted mutations } \\
\cline { 3 - 5 } sequenced & Protocol & $\begin{array}{l}\text { adjacent to } \\
\text { Primers }^{\mathrm{a}}\end{array}$ & $\begin{array}{l}\text { distant from } \\
\text { Primers }^{\mathrm{b}}\end{array}$ & Total \\
\hline 11 & one step & 0 & 1 & 1 \\
24 & two step & 14 & 2 & 16 \\
26 & megaprimer & 22 & 0 & 22 \\
\hline
\end{tabular}

${ }^{a}$ Consistent with Taq polymerase terminal transferase-like activity causing the mutations listed in this column, according to the mechanism described in the text and in Fig. 2.

${ }^{\mathrm{b}}$ Consistent with $\mathrm{Taq}$ polymerase misincorporation of nucleotides during template-dependent chain elongation.

\section{RESULTS AND DISCUSSION} found in $38(62 \%)$ of the 61 variants sequenced (single substitutions in 37 and patterns. One pattern consists of apparently random mutations distant from the PCR primers. These occur infrequently, in 3 out of 61 or $5 \%$ of the variants, and are most likely caused by Taq polymerase misincorporating deoxynucleotides during template-dependent chain elongation. ${ }^{(10,11)}$ Misincorporation mutations were not detected in products of the megaprimer method (4610 nucleotides sequenced from 26 clones) and occurred at a frequency of $0.06 \%$ per nucleotide sequenced for each of the one-step and the two-step procedures, comparable to frequencies found by others, $0.026 \%,^{(1)} 0.06 \%,{ }^{(2)}$ and $0.25 \% .{ }^{(6)}$ The fidelity of Taq polymerase under standard PCR conditions ranges from $0.1 \times 10^{-4}$ to $2.1 \times 10^{-4}$ errors/ bp. ${ }^{(12-14)}$ Therefore, the theoretical mutation frequency is predicted to be 0.04 $0.9 \%$ per nucleotide after 21 cycles of amplification. Our frequency of errors falls within this theoretical range, and, more importantly, the fidelity of Taq polymerase permits faithful replication of DNA used in PCR mutagenesis. We typically limit the number of essential (i.e., amino acid coding) nucleotides to less than 300 , thereby reducing the probability of finding an error from Taq polymerase misincorporation in any given clone. The three misincorporation mu$A: T \rightarrow G: C$ and one $G: C \rightarrow A: T$, consistent with previous observations that $A: T \rightarrow G: C$ mutations are the most common error by Taq polymerase. ${ }^{(11,14)}$

In contrast to misincorporations, the second group of mutations is common,
Unwanted nucleotide substitutions were two substitutions in 1) and fell into two tations detected are all transitions, two 
occurring in 36 out of 61 (59\%) of the variants sequenced (Table 1). This group consists of systematic substitutions of dAMP (34 out of 36 ) or dTMP ( 2 out of 36 ) for the nucleotide immediately adjacent to the 3 ' ends of the first-round PCR products. This pattern of mutation also is frequently observed by other investigators using different DNA templates and different sources of $\mathrm{Taq}$ polymerase (R. Olson and M. Stinski, University of Iowa, personal communication). The substitution of dAMP or dTMP adjacent to the $3^{\prime}$ ends of first-round PCR products likely results from the terminal transferase-like activity of Taq polymerase, which adds a single deoxynucleotide to the 3' ends of double-stranded DNA. ${ }^{(7)}$ Because restriction endonuclease digestion and cloning remove the 3 ' ends of the PCR product, the terminal transferase-like activity mechanism predicts that no unwanted systematic mutations will be found using the one-step method. This prediction was confirmed (Table 1).

The proposed mechanism for Taq polymerase terminal transferase-like activity-generated mutations is illustrated in Figure 2 using an example from our data. Taq polymerase terminal transferase-like activity preferentially adds $\mathrm{dAMP}^{(7)}$ to the $3^{\prime}$ ends of first-round double-stranded DNA PCR products (modified $\mathrm{a}+\mathrm{b}$ and modified $\mathrm{c}+\mathrm{d}$ products in Fig. 2). In the second round of PCR, modified first-round products prime each other. Taq polymerase extends the modified first-round products, fixing the dAMP substitution adjacent to the $3^{\prime}$ ends of the first-round products. The subsequent cycles of amplification copy the substitution to dAMP (modified $\mathrm{a}+\mathrm{d}$ products 1 and 2 in Fig. 2). The example in Figure 2 illustrates that when both first-round products are modified, the two-step procedure yields a maximum frequency of $100 \%$ terminal transferase-like activity mutated products. However, the mismatches at the positions adjacent to the $3^{\prime}$ ends of the firstround products localize the substitutions to opposite strands. After one round of amplification, the two strands segregate into separate products and each second-round product has at most only one of the two possible unwanted mutations ( $\mathrm{a}+\mathrm{d}$ products 1 and 2 in Fig. 2). Consistent with this proposed mechanism, we found no more than one mutation adjacent to the mutagenic

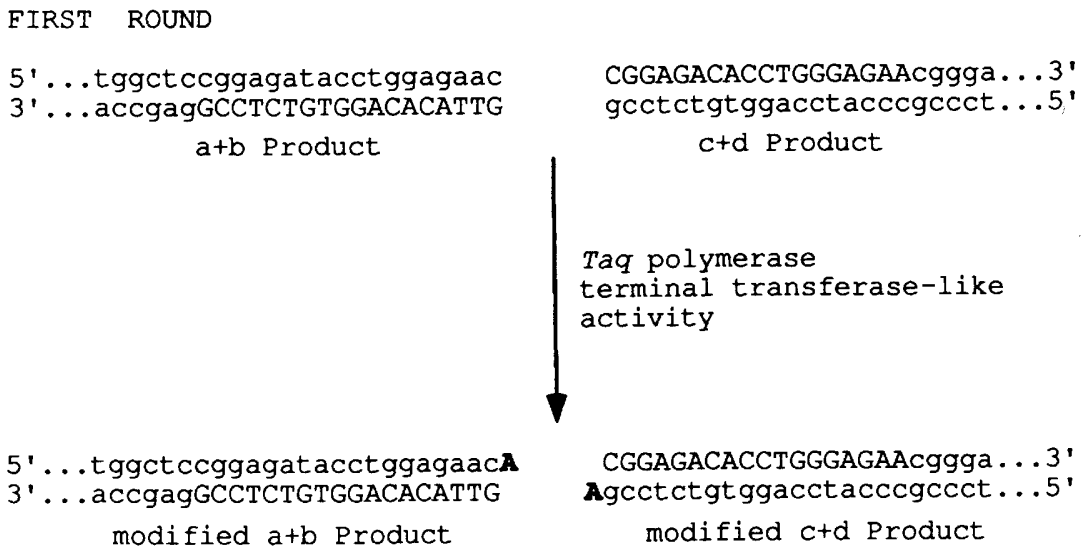

CGGAGACACCTGGGAGAAcggga ....3' Agcctctgtggacctacccgccct....5' modified $c+d$ Product

SECOND ROUND

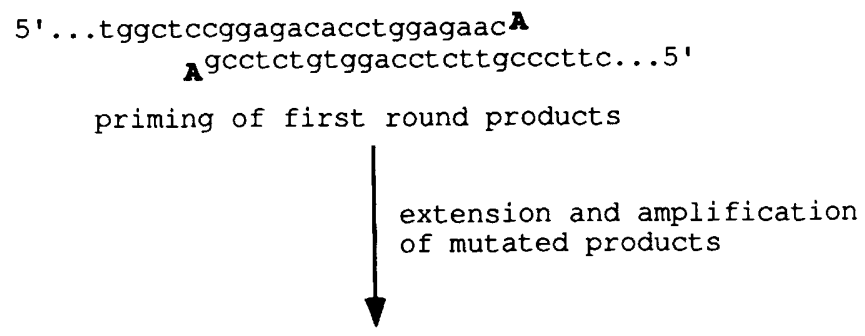

$5^{\prime}$...tgget ccggagacacctggagaacAggaag... 3'

$3^{\prime}$.... accgaggcet ctgtggacctcttgTccttc...5' $a+d$ Product 1

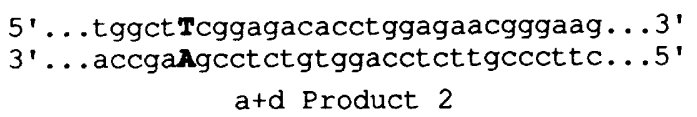

FIGURE 2 The proposed mechanism for terminal transferase-like activity-generated mutations, as illustrated for the two-step method. In the first round, PCR amplification creates a doublestranded DNA substrate for Taq polymerase terminal transferase-like activity. Taq polymerase preferentially adds dAMP to the $3^{\prime}$ ends of the first-round products. In the second round, these modified products serve as primers, but the added dAMP creates a $3^{\prime}$ mismatch. Taq polymerase tolerates the $3^{\prime} \mathrm{A} / \mathrm{C}$ mismatches and extends the DNA strand beyond the mismatch. After another cycle of amplification, the resulting $\mathrm{G} \rightarrow \mathrm{A}$ substitutions are seen in the $\mathrm{a}+\mathrm{d}$ products. Note that each added dAMP causes a $G \rightarrow A$ substitution in only one of the a $+d$ products. Because Taq polymerase terminal transferase-like activity preferentially adds dAMP to the 3 ' ends of doublestranded PCR products, few substitutions to dTMP, dGMP, and dCMP are seen. This example shows both first-round products as modified. However, some PCR products may remain unmodified by Taq polymerase terminal transferase-like activity. In addition, only the internal ends of the first-round PCR products are shown because the external ends are removed by restriction endonuclease digestion during cloning of the second-round product. Oligonucleotide primers are shown in capital letters, and terminal transferase-like activity added nucleotides and the resulting mutations are shown in bold capital letters.

primers for each PCR product sequenced for the two-step method.

In terminal transferase-like activity, Taq polymerase strongly prefers dATP as a substrate. ${ }^{(7)}$ Strikingly, 34 out of the 36
Taq polymerase terminal transferase-like activity-generated mutations are substitutions to dAMP, showing that dAMP is also preferentially added to the $3^{\prime}$ ends of double-stranded DNA during PCR mu- 
tagenesis; only two (6\%) of the substitutions are to dTMP and none are to dGMP or dCMP (Table 2). Kwok et al. demonstrated that a primer/template with a $3^{\prime}$ $\mathrm{A} / \mathrm{C}$ mismatch functions as well as a primer/template with no mismatch, but $3^{\prime}$ A:G or A:A mismatches function poorly. ${ }^{(15)}$ In contrast, we see a high frequency of $\mathrm{G} \rightarrow \mathrm{A}$ transitions and relatively high frequencies of $\mathrm{T} \rightarrow \mathrm{A}$ and $\mathrm{C} \rightarrow \mathrm{A}$ transversions (Table 2), indicating that $3^{\prime} \mathrm{A}: \mathrm{G}$ and A:A as well as A:C mismatches prime Taq polymerase chain elongation in our system.

If we assume that $3^{\prime} \mathrm{A}: \mathrm{C}$ primer/template mismatches prime with $100 \%$ efficiency, we can calculate how frequently dAMP is added to the $3^{\prime}$ ends of doublestranded DNA. In the two-step method, the maximum substitution frequency is $50 \%$ for each mutagenic primer (see Fig. 2 ). We observed $38 \%$ (12 of 32 ) out of the maximum possible $50 \% \mathrm{G} \rightarrow$ A substitutions. In the megaprimer method, the maximum possible frequency is $100 \%$ for the mutagenic primer. We observed $80 \%$ ( 16 of 20 ) out of the maximum pos-

TABLE 2 Substitutions to dAMP Are Highly Favored in Terminal Transferase-like ActivityGenerated Mutations

\begin{tabular}{ccc}
\hline Substitutions & $\begin{array}{l}\text { Observed/ } \\
\text { possible }\end{array}$ & $\begin{array}{l}\text { Corrected } \\
\text { substitution } \\
\text { frequency }^{\mathrm{a}}\end{array}$ \\
\hline $\mathrm{G} \rightarrow \mathrm{A}$ & $28 / 52$ & \\
Two step & $12 / 32$ & 0.75 \\
Megaprimer & $16 / 20$ & 0.80 \\
$\mathrm{~T} \rightarrow$ A & $2 / 3$ & 0.00 \\
Two step & $0 / 1$ & 1.00 \\
Megaprimer & $2 / 2$ & 0.27 \\
$\mathrm{C} \rightarrow$ A & $4 / 19$ & 0.50 \\
Two step & $2 / 15$ & \\
Megaprimer & $2 / 4$ & \\
Total & $34 / 74$ & \\
$\mathrm{G} \rightarrow$ T & $1 / 52$ & 0.00 \\
Two step & $0 / 32$ & 0.05 \\
Megaprimer & $1 / 20$ & 0.00 \\
$\mathrm{C} \rightarrow$ T & $1 / 19$ & 0.25 \\
Two step & $0 / 15$ & \\
Megaprimer & $1 / 4$ & \\
Total & $2 / 71$ & \\
\hline
\end{tabular}

${ }^{a}$ The corrected substitution frequency is equal to the (observed substitutions/possible substitutions) value divided by the maximum expected frequency of substitution $(0.50$ for the two-step method and 1.00 for the megaprimer method). sible $100 \%$ terminal transferase-like activity mutated products. Thus, Taq polymerase terminal transferase-like activity appears to add dAMP to $75-80 \%$ of the $3^{\prime}$ ends of double-stranded DNA during PCR. If Taq polymerase extends from $3^{\prime}$ A:C mismatches with less than perfect efficiency, then the frequency of Taq polymerase terminal transferase-like activity added dAMP would be even higher.

Taq polymerase terminal transferaselike activity preferentially adds dAMP to double-stranded DNA and Taq polymerase tolerates $3^{\prime}$ primer/template mismatches. These facts suggest two simple strategies to avoid or circumvent unwanted mutations in PCR mutagenesis. (1) Taq polymerase addition of dAMP to the 3 ' ends of PCR products has the effect of substituting dTMP at the deoxynucleotide position immediately preceding the $5^{\prime}$ end of the primer. Therefore, position the $5^{\prime}$ end of primers adjacent to either a dTMP or a position that can tolerate a change to dTMP (such as the wobble position of many amino acid codons). (2) When possible use the onestep method, in which the mutagenic primer also contains the restriction endonuclease site. We have successfully used primers of up to 50 deoxynucleotides in this procedure.

Using these suggestions, we have not seen mutations in six clones made with the $5^{\prime}$ end of primers adjacent to dTMP. Of nine clones made with the $5^{\prime}$ end of the primer adjacent to the wobble position, eight showed substitutions to dAMP, and one showed a substitution to dTMP adjacent to the 3 ' end of the firstround PCR product, consistent with Taq polymerase adding a dAMP or, less frequently, a dTMP to the 3 ' ends of the first-round PCR product. Using the onestep method, we have never seen a mutation adjacent to the primer.

In conclusion, this report discusses two classes of unwanted mutations generated during PCR amplification. The first class consists of misincorporation mutations that occur at a low frequency. The second class consists of terminal transferase-like activity-generated mutations. These occur frequently in procedures that use PCR products to prime subsequent rounds of PCR. Although not documented here, PCR recombination ${ }^{(3)}$ likely also suffers terminal transferaselike activity-generated mutations. However, this class of mutations is highly predictable and, hence, avoidable.

\section{ACKNOWLEDGMENTS}

We thank M. Stinski for a critical reading of this manuscript and Khen Van Mac for oligonucleotide synthesis. This work was supported by National Institutes of Health 1R29 AI27879-01A2, March of Dimes Basil O'Connor Award 5-741, and American Cancer Society JFRA 256.

\section{REFERENCES}

1. Ho, S.N., H.D. Hunt, R.M. Horton, J.K. Pullen, and L.R. Pease. 1989. Site-directed mutagenesis by overlap extension using the polymerase chain reaction. Gene 77: 51-59.

2. Sarkar, G. and S.S. Sommer. 1990. The "megaprimer" method of site-directed mutagenesis. Biotechniques 8: 404-407.

3. Horton, R.M., H.D. Hunt, S.N. Ho, J.K. Pullen, and L.R. Pease. 1989. Engineering hybrid genes without the use of restriction enzymes: Gene splicing by overlap extension. Gene 77: 61-68.

4. Zoller, M.J. and M. Smith. 1982. Oligonucleotide-directed mutagenesis using M13. derived vectors: An efficient and general procedure for the production of point mutations in any fragment of DNA. Nucleic Acids Res. 10: 6487-6499.

5. Kunkel, T.A., J.D. Roberts, and R.A. Zakour. 1987. Rapid and efficient site-specific mutagenesis without phenotypic selection. Methods Enzymol. 154: 367-382.

6. Saiki, R.K., D.H. Gelfand, S. Stoffel, S. Scharf, R. Higuchi, R.T Horn, K.B. Mullis, and H.A. Erlich. 1988. Primer-directed enzymatic amplification of DNA with a thermostable DNA polymerase. Science 239: 487-491.

7. Clark, J.M. 1988. Novel non-templated nucleotide addition reactions catalyzed by prokaryotic and euraryotic DNA polymerases. Nucleic Acids Res. 16: 9677-9686.

8. Maniatis, T., E.F. Fritsch, and J. Sambrook. 1982. Molecular cloning: A laboratory manual. Cold Spring Harbor Laboratory, Cold Spring Harbor, New York.

9. Adams, S.M. and R. Blakesly. 1991. Linear amplification DNA sequencing. Focus 13: $56-58$.

10. Dunning, A.M., P. Talmund, and S.E. Humphries. 1988. Errors in the polymerase chain reaction. Nucleic Acids Res. 16: 10393.

11. Tindall, K.R. and T.A Kunkel. 1988. Fidelity of DNA synthesis by the Thermus aquaticus DNA polymerase. Biochemistry 27: 6008-6013.

12. Eckert, K.A. and T. Kunkel. 1990. High fidelity DNA synthesis by Thermus aquaticus DNA polymerase. Nucleic Acids Res. 18: $3739-3744$.

13. Cariello, N.F., J.A. Swenberg, and T.R. Skopek. 1991. Fidelity of Thermococcus 
litoralis DNA polymerase (Vent) in PCR determined by denaturing gradient gel electrophoresis. Nucleic Acids Res. 19: 4193-4198.

14. Keohavong, P. and W.G. Thilly. 1989. Fidelity of DNA polymerases in DNA amplification. Proc. Natl. Acad. Sci. 86: 92539257.

15. Kwok, S., D.E. Kellog, N. McKinney, D. Spasic, L. Goda, C. Levenson, and J.J. Sninsky. 1990. Effects of primer-template mismatches on the polymerase chain reaction: Human immunodeficiency virus type 1 model studies. Nucleic Acids Res. 18: 999-1005.

Received July 28, 1992; accepted in revised form November 3, 1992. 


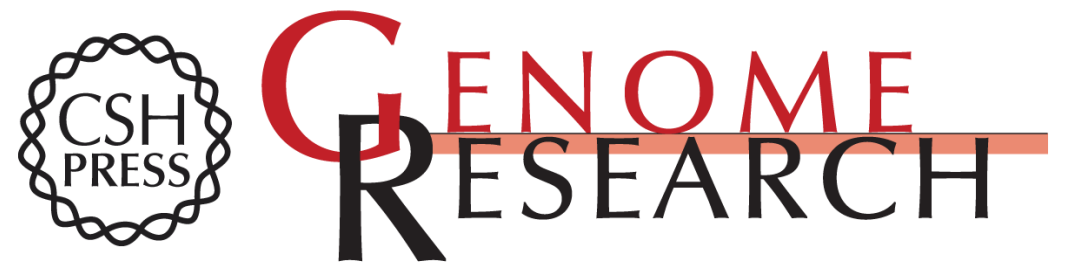

\section{Unwanted mutations in PCR mutagenesis: avoiding the predictable.}

K D Smith, A Valenzuela, J L Vigna, et al.

Genome Res. 1993 2: 253-257

Access the most recent version at doi:10.1101/gr.2.3.253

References This article cites 14 articles, 2 of which can be accessed free at:

http://genome.cshlp.org/content/2/3/253.full.html\#ref-list-1

License

Email Alerting Receive free email alerts when new articles cite this article - sign up in the box at the Service top right corner of the article or click here.

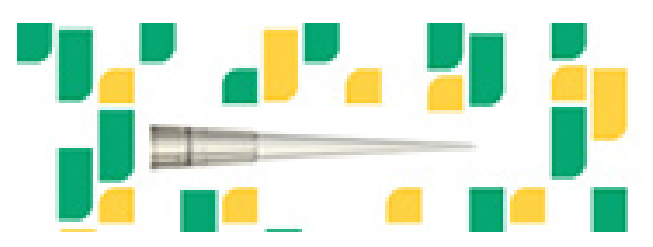

To subscribe to Genome Research go to: https://genome.cshlp.org/subscriptions 